\title{
Aggregated impact of allowance allocation and power dispatching on emission reduction
}

\author{
Chao JIANG ${ }^{1,2}$, Yusheng $\mathrm{XUE}^{2}$, Jie HUANG ${ }^{2}$, Feng XUE ${ }^{2}$, \\ Fushuan $\mathrm{WEN}^{3}$, Kang $\mathrm{LI}^{4}$
}

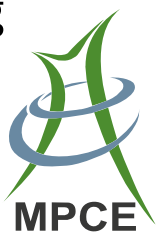

\begin{abstract}
Climate change has become one of the most important issues for the sustainable development of social well-being. China has made great efforts in reducing $\mathrm{CO}_{2}$ emissions and promoting clean energy. Pilot Emission Trading Systems (ETSs) have been launched in two provinces and five cities in China, and a national level ETS will be implemented in the third quarter of 2017 , with preparations for China's national ETS now well under way. In the meantime, a new round of China's electric power system reform has entered the implementation stage. Policy variables from both electricity and emission markets will
\end{abstract}

CrossCheck date: 19 May 2017

Received: 16 August 2016/Accepted: 19 May 2017/Published online: 15 September 2017

(C) The Author(s) 2017. This article is an open access publication

Yusheng XUE

xueyusheng@sgepri.sgcc.com.cn

Chao JIANG

jiangchao1@sgepri.sgcc.com.cn

Jie HUANG

huangjie1@sgepri.sgcc.com.cn

Feng XUE

xue-feng@sgepri.sgcc.com.cn

Fushuan WEN

fushuan.wen@gmail.com

Kang LI

K.LI@qub.ac.uk

1 Nanjing University of Science and Technology (NJUST), Nanjing 210094, China

2 State Grid Electric Power Research Institute (SGEPRI), Nanjing 211000, China

3 Universiti Teknologi Brunei (UTB), Brunei Muara, Brunei

4 Queen's University, Belfast, UK impose potential risks on the operation of generation companies (GenCos). Under this situation, by selecting key variables in each domain, this paper analyzes the combined effects of different allowance allocation methods and power dispatching models on power system emission. Key parameters are set based on a provincial power system in China, and the case studies are conducted based on dynamic simulation platform for macro-energy systems (DSMES) software developed by the authors. The selected power dispatching models include planned dispatch, energy saving power generation dispatch and economic dispatch. The selected initial allowance allocation methods in the emission market include the grandfathering method based on historical emissions and the benchmarking method based on actual output. Based on the simulation results and discussions, several policy implications are highlighted to help to design an effective emission market in China.

Keywords Emission trading system (ETS), Allowance allocation, Power dispatching, Generation company, Emission reduction

\section{Introduction}

The ever increasing concern of global climate change has brought intensive attention to emission reduction, which has become one of the most important issues for the sustainable development of social well-being [1]. The emission trading system (ETS), the clean development mechanism (CDM), and joint implementation (JI) are flexible emission reduction mechanisms put forward by the Kyoto Protocol in 1997, among which the ETS has been widely implemented by policy makers around the world. 
According to the Paris Agreement reached in 2015, governments worldwide will strengthen their emission control measures dealing with climate change threats, to limit global warming to less than 2 degrees Celsius compared to pre-industrial levels, and will also make efforts to limit the temperature increase to 1.5 degrees Celsius [2].

U.S.-China Joint Announcement on Climate Change was issued in November 2014. China intends to achieve the peaking of $\mathrm{CO}_{2}$ emissions around 2030, and plans to increase the share of non-fossil fuels in primary energy consumption to around $20 \%$ by 2030 . Heretofore, two provinces (Hubei and Guangdong) and five cities (Beijing, Tianjin, Shanghai, Chongqing, and Shenzhen) have launched pilot ETSs, and a national ETS will be launched in 2017.

China is still in the process of industrialization and urbanization, with a growing economy. According to the "China Electricity Industry Development Annual Report" issued by China Electricity Council (CEC), the national electricity consumption in 2015 has reached 5.55 trillion $\mathrm{kWh}$, with a year-on-year growth rate of $0.5 \%$. Although the year-on-year growth rate decreases compared with historical records, the demand is expected to continue increasing. As important parts of the energy sector and the major emission source, corporations in electricity sector are primary participants in emission markets [3]. To realize the low-carbon and sustainable power supply systems, power distribution and transmission expansion planning should consider emission constraints [4, 5] and the impact of an ETS, and the design and implementation of an ETS should also consider the development of the power system and the electricity market.

Initial allowance allocation is the cornerstone for an ETS, and the selection of allocation methods may have profound influences on the supply-demand relationship of participants in an ETS, and hence on the market dynamics. Other factors, such as the output variations of companies, may also change the supply-demand relationship. Currently, a new round of China's electric power system reform has entered the implementation stage, and GenCos' power output would be gradually determined by market exchange instead of generating plans determined by authorities.

There has been considerable research about the existing ETSs. Quantitative analyses have been done to estimate the market risk in [6], to assess the impact of the EU ETS on technological change in [7], to investigate the impacts of policy adjustments in the EU ETS on carbon prices [8], and to untangle the impacts of the EU ETS and the economic crisis [9]. A mixed complementarity problem model is used to assess the initial emission allowance allocation methods in the Korean electricity market in [10]. With respect to China's existing pilot ETSs, their allowance mechanism is compared with schemes in EU and California [11], historical data on the price and trading volume is applied to assess the financial performance of the Shenzhen carbon market [12] and the distinct features of the Hubei ETS are summarized in [13]. As regards China's future national ETS, a multi-regional computable general equilibrium (CGE) model is adopted to examine the effects of a nationwide carbon market on $\mathrm{CO}_{2}$ reduction efficiency under different emission reduction targets [14] and an online questionnaire has been conducted to identify the factors affecting companies' awareness and perception of the ETS [15], however quantitative analysis is still inadequate in this area. Considering the development of China's ETS and electricity markets, this paper develops several power dispatching and allowance allocation scenarios that are likely to happen in the future. Based on a simplified generation mix of one provincial power system in China, several scenarios are simulated and analyzed. With regard to the simulation results and discussions, several policy implications are highlighted to help to design an effective emission market in China.

The remainder of this paper is organized as follows. Section 2 gives a brief review of the existing research on the allowance allocation methods for the GenCos and China's power dispatching models. Section 3 introduces the simulation platform and methodology, allowance allocation models, and power dispatching models, and related data and parameters are also given. Section 4 highlights the policy implications for China's national emission market based on the case study results. The final section concludes this paper.

\section{Background and models}

\subsection{Allowance allocation models}

There are two methods for allowance allocation in an emission market: free allocation or auction, each having its pros and cons. Auction is generally recognized as a more equitable method, which provides more incentives for emission reductions [16], and can produce an explicit reference price for the secondary market [17]. Free allocation is more acceptable for stakeholders as it does not significantly increase the emission cost. At the initial stage of an ETS, free allocation is more favorable [18].

Grandfathering and benchmarking are the two major free allocation methods. Under grandfathering, the allocation results are predictable for all participants. However, the past emission reduction efforts cannot be considered in the allocation, which is unfair for low carbon enterprises. Besides, grandfathering cannot be applied to newly-built units [19]. The basic idea of benchmarking is that the same benchmark value is set for enterprises that produce the same products [20]. Benchmarking can be based on either 
historical or actual output. If the future output levels are greatly influenced by various factors, the benchmarking method based on actual output levels is robust to output variations. Benchmarking requires more information than grandfathering and it is complex to set appropriate benchmarks for different industries, which makes it hard to apply at the initial stage of an ETS [21].

In the pilot ETSs in China, a majority of allowances are allocated for free, with a relatively small portion being auctioned in Shenzhen and Guangdong. Grandfathering is applied to allocate allowances for cogeneration units in Guangdong, and benchmarking is adopted to allocate allowances for coal-fired and gas-fired units in Shanghai. As China has a steadily growing economy, a benchmarking method based on actual output (rather than historical output) is planned to allocate allowances for generation companies in the national level ETS, in order to balance emission reduction and economic growth.

Considering the practice in pilot ETSs and the proposed allocation method in a national level ETS in China, the two allocation methods considered in this paper are a grandfathering method based on historical emissions and a benchmarking method based on actual output.

\subsubsection{Grandfathering based on historical emissions}

By adopting the grandfathering method based on historical emissions, free allowances are allocated based on emitters' historical emissions:

$Q_{\mathrm{ea}, i}=Q_{\mathrm{he}, i} \lambda_{i}$

where $Q_{\mathrm{ea}, i}$ is the quantity of freely allocated allowances for emitter $i ; Q_{\mathrm{he}, i}$ is the historical emission of emitter $i ; \lambda_{i}$ is the free allocation factor for emitter $i$.

\subsubsection{Benchmarking based on actual output}

By adopting the benchmarking method based on actual output, free allowances are allocated based on emitters' actual output multiplied by a benchmark value. The benchmark value can be the average emission rate, the advanced emission rate in the industry, or the historical emission rate of an emitter:

$Q_{\mathrm{ea}, i}=Q_{\mathrm{ao}, i} B_{i} \lambda_{i}$

where $Q_{\mathrm{ao}, i}$ is the actual output of emitter $i ; B_{i}$ is the benchmark value for emitter $i$.

\subsection{Power dispatching models}

Since 1985, electricity demand has increased at a rapid pace along with China's rapid economic development. In order to fill in the growing gap between the electricity supply and demand, China implemented a funding policy for power generation [22]. To guarantee the performance of investments, equal distribution of generation quantity for different power units became the primary task of power dispatching, which significantly promoted the development of the power industry under the conditions at that time. By 1995, the total installed capacity of China had exceeded 200 million kilowatts, and the power shortage problem at the national level had been basically solved. In 2003, in order to adapt to the new situation after China's electric power system reform since 2002, the State Electricity Regulatory Commission (SERC) of China put forward the "Open, Just and Fair" power dispatching principles. Almost the same amount of annual generation utilization hours would be allocated to power units within the same category, without considering the differences in efficiency among power units. On one hand, low-efficiency and highemission units could get enough earnings without technical reform, and on the other hand, high-efficiency and lowemission units would be under economic pressure, resulting in a lack of incentives to invest in efficient and environmentally friendly power units [23]. Since the annual utilization hours of power units are determined by authorities and power dispatching centers are responsible for dispatching power units using a consistent process [24], it is essentially a planned dispatch. For easy reference, this power dispatch model conforming to "Open, Just and Fair" principles will be called planned dispatch (PD) in this paper. PD is still the major power dispatching model in China.

In response to the growing demand for energy conservation and emission reduction, "Energy Saving Power Generation Dispatching Measures (Trial)" were issued in 2007, and five provinces (Jiangsu, Henan, Sichuan, Guangdong and Guizhou) were selected as pilots to implement the Energy Saving Generation Dispatch (ESGD) method [25]. ESGD denotes that on the premise of secure and reliable power supply, in accordance with the energy saving and economic efficiency principles, renewable energy resources have priority of dispatch to generate electricity, followed by fossil power generation resources, in ascending order of emission intensity to minimize the fuel consumption and emissions of pollutants [26].

On March 15, 2015, the China State Council issued the "Several Opinions of the CPC Central Committee and the State Council on Further Deepening the Reform of the Electric Power System", also known as "Policy No. 9", and determined the direction of electric reform, to promote electricity bidding to put the market oriented allocation of resources into full play, which was a confronting change to the past planned dispatching model [27]. The competition among GenCos is likely to become intense given that the electricity supply is abundant. GenCos will apply more 
attention to improving the efficiency and management of power plants for competitive advantage. Therefore, the dispatching model is likely to be gradually transformed into economic dispatch (ED) in the future.

Considering the development of China's power dispatching models, PD, ESGD and ED are taken into account in this paper. The unit startup and shutdown, ramp rates, minimum output, and the transmission constraints are not considered in the three dispatching models. The deviations introduced by these simplifications are acceptable as this paper focuses on long-term problems.

\subsubsection{Planned dispatch}

Under PD, based on the forecast annual load, the corresponding authorities approve the annual utilization hours for each generation category, which will be successively decomposed into the monthly generating plan and the daily generating plan combined with appropriate adjustments [28], which can be described by (3). For simplicity, this paper does not consider load prediction deviations, and the simulation program will assign the annual utilization hours to the daily generating plan according to the daily load rate, in order to meet the "Open, Just and Fair" principles.

$\left|\left(\sum_{t=1}^{T} h_{i, t}-H_{i}\right) / H_{i}\right| \leq \Delta H \quad \forall i \in N$

where $h_{i, t}$ is the actual utilization hours of unit $i$ at day $t ; H_{i}$ is the approved annual utilization hours for unit $i ; \Delta H$ is the relative deviation limit; $T$ is the number of days in one year; $N$ is the number of units to be dispatched.

The electricity prices in PD are determined by the price regulator according to the benchmark price policy, on the basis of the economic life cycle of the power units, and reasonable economic compensation and profits.

\subsubsection{Energy saving generation dispatch}

According to the official policy documents, the objective function of energy saving generation dispatch (ESGD) can be described as minimizing the fuel consumption $f_{f}$ and emissions of pollutants $f_{e}$, which can be formulated by (4)(6) according to reference [29].

$\min \boldsymbol{F}=\left[\min f_{f}, \min f_{e}\right]^{\mathrm{T}}$

$f_{f}=\sum_{t=1}^{T} \sum_{i=1}^{N} q_{i, t} \lambda_{f, i}$

$f_{e}=\sum_{t=1}^{T} \sum_{i=1}^{N} q_{i, t} \lambda_{e, i}$ where $q_{i, t}$ is the output of unit $i$ at day $t ; \lambda_{f, i}$ is the fuel consumption rate of unit $i ; \lambda_{e, i}$ is emission rate of unit $i$. In order to facilitate the implementation of the ESDG, a priority schedule order shown in Table 1 is proposed in the official policy documents. As in PD, the electricity prices under ESGD are also determined by the benchmark price policy.

It is important to note that in actual practice of ESGD, units are not dispatched corresponding to this table in a strict way, as there are long-term contracts that were signed before the policy came into practice. In this paper, in order to highlight the effect of ESGD, all units are dispatched strictly in accordance to the priority schedule order.

\subsubsection{Economic dispatch}

The objective function of ED is to minimize the generation cost as follows.

$\min f_{c}=\sum_{t=1}^{T} \sum_{i=1}^{N} q_{i, t} c_{i}$

where $f_{c}$ is a linear cost function; $c_{i}$ is the marginal generation cost of unit $i$, which consists of marginal fuel cost and marginal emission cost as follows.

$c_{i}=\lambda_{f, i} p_{f, i}+\lambda_{e, i} p_{e}$

where $p_{f, i}$ is the fuel price consumed by unit $i ; p_{e}$ is the carbon price.

Whether allocated for free or not, the economic value of allowances includes the opportunity cost of using allowances that could otherwise be sold in the market. Therefore, the emission cost here refers to the opportunity cost, which is the product of the emission rate and carbon price.

Table 1 Priority schedule order of the generation units in ESGD

\begin{tabular}{|c|c|}
\hline Order & Types of the power units \\
\hline 1 & $\begin{array}{l}\text { Renewable units with little adjustment capability including } \\
\text { wind, solar, oceanic energy and hydro units }\end{array}$ \\
\hline 2 & $\begin{array}{l}\text { Renewable units with adjusting capacities including hydro } \\
\text { units, biomass and geothermal energy units }\end{array}$ \\
\hline 3 & Nuclear units \\
\hline 4 & $\begin{array}{l}\text { Combined cycle thermal units whose generation is decided by } \\
\text { heating load and resource comprehensive exploitation units } \\
\text { or in other words, waste power units }\end{array}$ \\
\hline 5 & Gas-fired and coal gasification units \\
\hline 6 & $\begin{array}{l}\text { Other thermal units including a combined cycle thermal unit } \\
\text { without heating load }\end{array}$ \\
\hline 7 & Oil-fired units \\
\hline
\end{tabular}


Table 2 Key parameters of GenCos

\begin{tabular}{|c|c|c|c|c|c|c|c|}
\hline \multirow[t]{2}{*}{ GenCos } & \multicolumn{2}{|l|}{ Fuel } & \multicolumn{3}{|l|}{ Technical } & \multicolumn{2}{|l|}{ Economic } \\
\hline & Fuel price & $\begin{array}{l}\text { Installed capacity } \\
\text { (MW) }\end{array}$ & $\begin{array}{l}\text { Fuel } \\
\text { consumption } \\
\text { rate }\end{array}$ & $\begin{array}{l}\text { Emission rate } \\
(\mathrm{g} / \mathrm{kWh})\end{array}$ & $\begin{array}{l}\text { Marginal fuel cost } \\
(¥ / \mathrm{kWh})\end{array}$ & $\begin{array}{l}\text { Electricity price } \\
(¥ / \mathrm{kWh})\end{array}$ & $\begin{array}{l}\text { Annual } \\
\text { utilization (hour) }\end{array}$ \\
\hline COAL_H & $\begin{array}{l}591.00 \\
(¥ / \text { ton })\end{array}$ & $300 \times 17$ & $321(\mathrm{~g} / \mathrm{kWh})$ & 946 & 0.190 & 0.436 & 5325 \\
\hline COAL_M & & $600 \times 5$ & $298(\mathrm{~g} / \mathrm{kWh})$ & 879 & 0.176 & & 5460 \\
\hline COAL_L & & $900 \times 6$ & $278(\mathrm{~g} / \mathrm{kWh})$ & 820 & 0.164 & & 5559 \\
\hline GAS_H & $\begin{array}{l}1.77 \\
\left(¥ / \mathrm{m}^{3}\right)\end{array}$ & $60 \times 10$ & $\begin{array}{l}0.211 \\
\quad\left(\mathrm{~m}^{3} / \mathrm{kWh}\right)\end{array}$ & 415 & 0.373 & 0.504 & 3387 \\
\hline GAS_L & & $800 \times 4$ & $\begin{array}{l}0.180 \\
\quad\left(\mathrm{~m}^{3} / \mathrm{kWh}\right)\end{array}$ & 354 & 0.319 & & 4336 \\
\hline OIL & $\begin{array}{l}5383.00 \\
\quad(¥ / \text { ton })\end{array}$ & $100 \times 8$ & 168 (g/kWh) & 528 & 0.904 & 1.140 & 2391 \\
\hline
\end{tabular}

\section{Simulation methodology}

\subsection{Simulation tool and method}

The research team of the authors has developed a novel simulation tool dynamic simulation platform for macroenergy systems (DSMES) that supports the dynamic interactive simulation among cross-domain models, computer agents and human participants [30]. As DSMES is an extensible platform, the emission allowance pricing model are added to DSMES for the purpose of emission market research [31]. Moreover, supported by DSMES, experiments with human subjects were conducted and major driving factors of emission trading were extracted, which could aid the construction of multi-agent stochastic models with the same distribution characteristics [32, 33]. In this paper, we implement different power dispatching models and allowance allocation models in DSMES, based on which all participants' mathematical models are constructed and key parameters are set. Since the time sequence can be adjusted flexibly, the simulations are conducted based on a customizable time sequence of related events, such as allowance allocation, bid submitting, market clearing, emission calculation, and so on.

\subsection{Models and parameters}

\subsubsection{Generation mix}

The power system model in this paper is based on a simplified generation mix of one provincial power system in China. Six GenCos are included in the generation mix: COAL_H, COAL_M and COAL_L own coal-fired units, GAS_H and GAS_L own gas-fired units, and OIL owns oil-fired units. Parameters of the six GenCos can be found

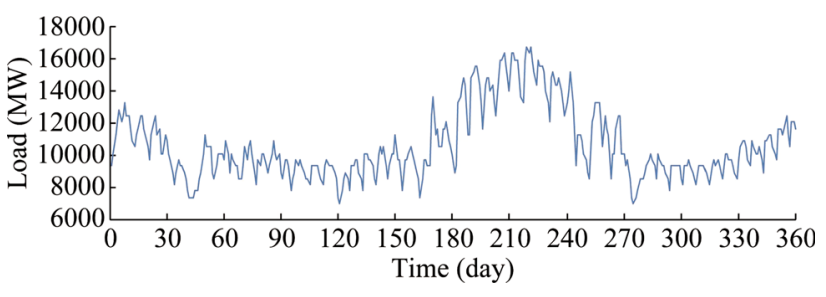

Fig. 1 Daily load curve

in Table 2. The marginal fuel cost is calculated based on fuel prices and consumption rates. The simulation time span is one year, consisting of day-to-day power market and emission market transactions. For simplicity and to focus the study on the overall performance of emission and electricity markets, no strategic behaviors are considered in either market and GenCos report their marginal generation cost to the electricity market and purchase or sell the allowances according to their emission balance. The daily load curve is also based on actual data from the provincial power system in China, and it is shown in Fig. 1 over a 1 -year modeling period.

\subsubsection{Selected carbon price levels}

The average carbon price in the seven pilot ETSs in China was $43 ¥ /$ ton by the end of October 2014 . To provide a context for this figure, under ED, the priority schedule order of units may be changed by the emission cost when the carbon price level reaches threshold values that depend on the parameters of GenCos. Three threshold prices calculated from the data in Table 2 are 220, 347, $427 ¥ /$ ton.

Compared with the average carbon price of $43 ¥ /$ ton, the threshold prices seem too high for case studies. However, the maximum carbon price in the EU ETS was $32 € /$ ton achieved in 2006 , equivalent to $319.36 ¥ /$ ton (according to 
Table 3 Key parameters of the benchmarking method

\begin{tabular}{lll}
\hline GenCos & Benchmark value $\left(\mathrm{tCO}_{2} / \mathrm{MWh}\right)$ & Free allocation factor \\
\hline COAL_H & 0.8187 & $100 \%$ \\
COAL_M & 0.7953 & \\
COAL_L & 0.7563 & \\
GAS_H & 0.3800 & \\
GAS_L & & \\
\hline
\end{tabular}

2006 exchange rate $9.98 ¥ / €)$, and through questionnaires, Point Carbon indicates that the carbon price in the EU ETS needs to be $38 € /$ ton to achieve effective emission reduction [34]. Therefore, the threshold prices above are in a reasonable range.

\subsubsection{Allowance allocation parameters}

Benchmark value selection is based on the "Allocation and Management Plan Shanghai 2013-2015" issued by Shanghai Municipal Development and Reform Commission in November 2014. The benchmark value and free allocation factor for units can be found in Table 3. Oil-fired units are not included in the Shanghai ETS. Based on the total allocated allowances under benchmarking in a $\mathrm{BaU}$ scenario, the free allocation factor under grandfathering is calculated as follows: first, as gas-fired units are lowemission, the free allocation factor for gas-fired unit is set to $100.0 \%$; then the total allowances minus those for gasfired units are allowances for coal-fired units, which are then divided by total historical emissions of coal-fired units to calculate the free allocation factor under grandfathering which is $90.0 \%$.

\section{Case studies}

\subsection{Scenarios settings}

The two alternative allocation methods considered are the grandfathering method based on historical emissions and the benchmarking method based on actual output. The three alternative power dispatching models considered are PD, ESGD and ED.

China's current primary power dispatching model is PD, and a national ETS is yet to be implemented. Therefore, PD without emission trading (ET) is set as the $\mathrm{BaU}$ scenario, from which the simulation results are used as basic data for two allocation methods in other scenarios. The impact of different allowance allocation methods is studied in the PD with ET scenario, the ESDG with ET scenario and the ED with ET scenario. Under ED, as the carbon price may
Table 4 Simulation results (PD without ET)

\begin{tabular}{llll}
\hline GenCos & $\begin{array}{l}\text { Generation } \\
\text { (billion kWh) }\end{array}$ & $\begin{array}{l}\text { Profit in electricity } \\
\text { market (billion } ¥)\end{array}$ & $\begin{array}{l}\text { Emissions } \\
\text { (million ton) }\end{array}$ \\
\hline COAL_H & 27.16 & 6.68 & 25.69 \\
COAL_M & 16.38 & 4.26 & 14.40 \\
COAL_L & 30.02 & 8.17 & 24.62 \\
GAS_H & 2.03 & 0.27 & 0.84 \\
GAS_L & 13.88 & 2.57 & 4.91 \\
OIL & 1.91 & 0.45 & 1.01 \\
TOTAL & 91.38 & 22.40 & 71.47 \\
\hline
\end{tabular}

change the priority schedule order in the electricity market, the effects of different carbon price levels can be analyzed.

\subsection{Simulation results}

\subsubsection{Scenario 1: PD without ET (BaU scenario)}

The installed capacity of coal-fired units accounts for $74.6 \%$ of the total capacity of thermal power units and the annual utilization hours of coal-fired units are more than those of gas-fired units. Thus in this scenario, the emissions of GenCo COAL_H, COAL_M and COAL_L account for $90.5 \%$ of the total system emissions, the simulation results can be found in Table 4.

\subsubsection{Scenario 2: PD with ET}

An ETS is introduced in this scenario on the basis of the $\mathrm{BaU}$ scenario. As the dispatching model remains unchanged, the actual generation output of units is the same as the historical pattern and the allocation results of grandfathering and benchmarking are similar.

Compared to the allocation results with grandfathering, GenCos with higher energy efficiency within the same category can obtain more allowances with benchmarking, such as COAL_L among the coal-fired GenCos and GAS_L among the gas-fired GenCos as shown in Table 5. In this scenario, carbon prices cannot change GenCos' profit in the electricity market, but can change GenCos' profit in the emission market. With a carbon price of $427 ¥ /$ $\mathrm{t}$ and benchmarking, the expenditure of COAL_H in the emission market accounts for $22.1 \%$ of its profit in the electricity market.

\subsubsection{Scenario 3: ESGD with ET}

Under ESGD, as units are dispatched based on fuel consumption rates from low to high, so the generation output of COAL_L, GAS_H and GAS_L increase 
Table 5 Simulation results (PD with ET)

\begin{tabular}{|c|c|c|c|c|c|c|c|}
\hline \multirow[t]{2}{*}{ GenCos } & \multirow{2}{*}{$\begin{array}{l}\text { Generation } \\
\text { (billion } \mathrm{kWh} \text { ) }\end{array}$} & \multirow{2}{*}{$\begin{array}{l}\text { Profit in the electricity } \\
\text { market (billion ¥) }\end{array}$} & \multirow{2}{*}{$\begin{array}{l}\text { Emissions } \\
\text { (million ton) }\end{array}$} & \multicolumn{2}{|c|}{ Grandfathering (million ton) } & \multicolumn{2}{|c|}{ Benchmarking (million ton) } \\
\hline & & & & $\begin{array}{l}\text { Allowances } \\
\text { allocated }\end{array}$ & $\begin{array}{l}\text { Emission } \\
\text { balance }\end{array}$ & $\begin{array}{l}\text { Allowances } \\
\text { allocated }\end{array}$ & $\begin{array}{l}\text { Emission } \\
\text { balance }\end{array}$ \\
\hline COAL_H & 27.16 & 6.68 & 25.69 & 23.13 & -2.56 & 22.24 & -3.45 \\
\hline COAL_M & 16.38 & 4.26 & 14.40 & 12.96 & -1.44 & 13.03 & -1.37 \\
\hline COAL_L & 30.02 & 8.17 & 24.62 & 22.17 & -2.45 & 22.70 & -1.92 \\
\hline GAS_H & 2.03 & 0.27 & 0.84 & 0.84 & 0.00 & 0.77 & -0.07 \\
\hline GAS_L & 13.88 & 2.57 & 4.91 & 4.91 & 0.00 & 5.27 & 0.36 \\
\hline OIL & 1.91 & 0.45 & 1.01 & l & I & l & I \\
\hline TOTAL & 91.38 & 22.40 & 71.47 & 64.01 & -6.45 & 64.01 & -6.45 \\
\hline
\end{tabular}

Table 6 Simulation results (ESGD with ET)

\begin{tabular}{|c|c|c|c|c|c|c|c|}
\hline \multirow[t]{2}{*}{ GenCos } & \multirow{2}{*}{$\begin{array}{l}\text { Generation } \\
\text { (billion } \mathrm{kWh} \text { ) }\end{array}$} & \multirow{2}{*}{$\begin{array}{l}\text { Profit in the electricity } \\
\text { market (billion } ¥ \text { ) }\end{array}$} & \multirow{2}{*}{$\begin{array}{l}\text { Emissions } \\
\text { (million ton) }\end{array}$} & \multicolumn{2}{|c|}{ Grandfathering (million ton) } & \multicolumn{2}{|c|}{ Benchmarking (million ton) } \\
\hline & & & & $\begin{array}{l}\text { Allowances } \\
\text { allocated }\end{array}$ & $\begin{array}{l}\text { Emission } \\
\text { balance }\end{array}$ & $\begin{array}{l}\text { Allowances } \\
\text { allocated }\end{array}$ & $\begin{array}{l}\text { Emission } \\
\text { balance }\end{array}$ \\
\hline COAL_H & 3.13 & 0.78 & 2.99 & 23.13 & 20.14 & 2.59 & -0.4 \\
\hline COAL_M & 9.69 & 2.52 & 8.51 & 12.96 & 4.45 & 7.71 & -0.8 \\
\hline COAL_L & 45.27 & 12.31 & 37.12 & 22.17 & -14.95 & 34.24 & -2.88 \\
\hline GAS_H & 5.26 & 0.69 & 2.18 & 0.84 & -1.34 & 2 & -0.18 \\
\hline GAS_L & 28.03 & 5.19 & 9.92 & 4.91 & -5.01 & 10.65 & 0.73 \\
\hline OIL & 0.00 & 0.00 & 0.00 & l & I & l & I \\
\hline TOTAL & 91.38 & 21.49 & 60.72 & 64.01 & 3.29 & 57.19 & -3.53 \\
\hline
\end{tabular}

significantly, resulting in the total emissions decreasing $15.0 \%$ compared to those of the BaU scenario. Due to its lowest dispatch priority, GenCo OIL does not generate power during the whole year shown in Table 6. As for Scenario 2, the carbon price still cannot change GenCos' profit in the electricity market.

\subsubsection{Scenario 4: ED with ET}

Under ED, the introduction of an emission cost can change the clearing price in the electricity market. Four different carbon price levels are analyzed in this scenario.

When the carbon price equals $43 ¥ /$ ton, the generation of COAL_H, COAL_M and COAL_L accounts for $98.4 \%$ of the total generation. As they are high emission units, the system emissions increase by $9.0 \%$ compared to those in the BaU scenario. The results are shown in Table 7.

As the carbon price rises, low-emission units are more competitive, resulting in lower system emissions shown in Tables 8, 9 and 10. When the carbon price increases to 427 $¥ /$ ton, the system emissions are close to those under ESGD. Compared with grandfathering, many fewer allowances are allocated to high-emission units under benchmarking, which alters their emission balance from surplus to shortage.

Under ED, a rising carbon price will not only affect GenCos' profits in the emission market, but also in the electricity market. With the emission trading profits continuing to rise, GenCos should focus more on how to manage carbon assets when the carbon price is high enough.

\subsection{Discussions and policy implications}

\subsubsection{Variations of power dispatching models should be considered when choosing allowance allocation models}

If the power dispatching model and the power demand remain unchanged, different allocation methods will have minor influences on the simulation results. However, if the power dispatching model changes, for example under ESGD or ED, GenCos' annual emission unbalance varies significantly under different allocation methods.

The defect of the grandfathering method based on historical emissions is that past efforts to reduce emissions are overlooked. However, if allocated by grandfathering, high- 
Table 7 Simulation results (ED with ET, carbon price is $43 ¥ /$ ton)

\begin{tabular}{|c|c|c|c|c|c|c|c|}
\hline \multirow[t]{2}{*}{ GenCos } & \multirow{2}{*}{$\begin{array}{l}\text { Generation } \\
\text { (billion } \mathrm{kWh} \text { ) }\end{array}$} & \multirow{2}{*}{$\begin{array}{l}\text { Profit in the electricity } \\
\text { market (billion } ¥ \text { ) }\end{array}$} & \multirow{2}{*}{$\begin{array}{l}\text { Emissions } \\
\text { (million ton) }\end{array}$} & \multicolumn{2}{|c|}{ Grandfathering (million ton) } & \multicolumn{2}{|c|}{ Benchmarking (million ton) } \\
\hline & & & & $\begin{array}{l}\text { Allowances } \\
\text { allocated }\end{array}$ & $\begin{array}{l}\text { Emission } \\
\text { balance }\end{array}$ & $\begin{array}{l}\text { Allowances } \\
\text { allocated }\end{array}$ & $\begin{array}{l}\text { Emission } \\
\text { balance }\end{array}$ \\
\hline COAL_H & 16.94 & 1.26 & 16.02 & 23.13 & 7.11 & 13.87 & -2.15 \\
\hline COAL_M & 25.72 & 1.67 & 22.61 & 12.96 & -9.65 & 20.46 & -2.15 \\
\hline COAL_L & 47.30 & 3.62 & 38.79 & 22.17 & -16.62 & 35.77 & -3.02 \\
\hline GAS_H & 0.00 & 0.00 & 0.00 & 0.84 & 0.84 & 0 & 0 \\
\hline GAS_L & 1.42 & 0.02 & 0.51 & 4.91 & 4.4 & 0.55 & 0.04 \\
\hline OIL & 0.00 & 0.00 & 0.00 & l & l & l & l \\
\hline TOTAL & 91.38 & 6.57 & 77.93 & 64.01 & -13.92 & 70.65 & -7.28 \\
\hline
\end{tabular}

Table 8 Simulation results (ED with ET, carbon price is $220 ¥ /$ ton)

\begin{tabular}{|c|c|c|c|c|c|c|c|}
\hline \multirow[t]{2}{*}{ GenCos } & \multirow{2}{*}{$\begin{array}{l}\text { Generation } \\
\text { (billion } \mathrm{kWh} \text { ) }\end{array}$} & \multirow{2}{*}{$\begin{array}{l}\text { Profit in the electricity } \\
\text { market (billion } ¥ \text { ) }\end{array}$} & \multirow{2}{*}{$\begin{array}{l}\text { Emissions } \\
\text { (million ton) }\end{array}$} & \multicolumn{2}{|c|}{ Grandfathering (million ton) } & \multicolumn{2}{|c|}{ Benchmarking (million ton) } \\
\hline & & & & $\begin{array}{l}\text { Allowances } \\
\text { allocated }\end{array}$ & $\begin{array}{l}\text { Emission } \\
\text { balance }\end{array}$ & $\begin{array}{l}\text { Allowances } \\
\text { allocated }\end{array}$ & $\begin{array}{l}\text { Emission } \\
\text { balance }\end{array}$ \\
\hline COAL_H & 4.28 & 0.90 & 4.07 & 23.13 & 19.06 & 3.52 & -0.55 \\
\hline COAL_M & 25.72 & 5.58 & 22.61 & 12.96 & -9.65 & 20.46 & -2.15 \\
\hline COAL_L & 47.30 & 10.82 & 38.79 & 22.17 & -16.62 & 35.77 & -3.02 \\
\hline GAS_H & 0.00 & 0.00 & 0.00 & 0.84 & 0.84 & 0 & 0 \\
\hline GAS_L & 14.08 & 1.10 & 4.98 & 4.91 & -0.07 & 5.35 & 0.37 \\
\hline OIL & 0.00 & 0.00 & 0.00 & l & l & l & l \\
\hline TOTAL & 91.38 & 18.40 & 70.45 & 64.01 & -6.44 & 65.10 & -5.35 \\
\hline
\end{tabular}

Table 9 Simulation results (ED with ET, carbon price is $347 ¥ /$ ton)

\begin{tabular}{|c|c|c|c|c|c|c|c|}
\hline \multirow[t]{2}{*}{ GenCos } & \multirow{2}{*}{$\begin{array}{l}\text { Generation } \\
\text { (billion } \mathrm{kWh} \text { ) }\end{array}$} & \multirow{2}{*}{$\begin{array}{l}\text { Profit in the electricity } \\
\text { market (billion } ¥ \text { ) }\end{array}$} & \multirow{2}{*}{$\begin{array}{l}\text { Emissions } \\
\text { (million ton) }\end{array}$} & \multicolumn{2}{|c|}{ Grandfathering (million ton) } & \multicolumn{2}{|c|}{ Benchmarking (million ton) } \\
\hline & & & & $\begin{array}{l}\text { Allowances } \\
\text { allocated }\end{array}$ & $\begin{array}{l}\text { Emission } \\
\text { balance }\end{array}$ & $\begin{array}{l}\text { Allowances } \\
\text { allocated }\end{array}$ & $\begin{array}{l}\text { Emission } \\
\text { balance }\end{array}$ \\
\hline COAL_H & 3.15 & 1.04 & 2.99 & 23.13 & 20.14 & 2.59 & -0.40 \\
\hline COAL_M & 12.60 & 4.07 & 11.08 & 12.96 & 1.88 & 10.03 & -1.05 \\
\hline COAL_L & 46.45 & 14.93 & 38.10 & 22.17 & -15.93 & 35.14 & -2.96 \\
\hline GAS_H & 1.15 & 0.17 & 0.48 & 0.84 & 0.36 & 0.44 & -0.04 \\
\hline GAS_L & 28.03 & 4.65 & 9.92 & 4.91 & -5.01 & 10.65 & 0.73 \\
\hline OIL & 0.00 & 0.00 & 0.00 & l & / & I & / \\
\hline TOTAL & 91.38 & 24.86 & 62.57 & 64.01 & 1.44 & 58.85 & -3.72 \\
\hline
\end{tabular}

emission GenCos can be compensated for lost revenue, resulting from reduced generation, by selling the consequent surplus allowances, which can be regarded as a viable economic compensation mechanism.

The benchmarking method based on actual output is robust to dispatching model variations, so the emission balance of each GenCos is roughly equivalent and easy to predict. On the other hand, it may reduce the participants' trading enthusiasm in the emission market, affecting that market's liquidity.

\subsubsection{Current carbon price is inadequate to stimulate low carbon technology}

The simulation results in scenario 4 illustrate the carbon price incentives for technological innovation. For the generation mix considered in this paper, only when the carbon price is higher than $220 ¥ /$ ton can the priority schedule order of power units be changed. The average price of China’s pilot emission market (43 ¥/ton) and the recent EU ETS carbon price (about $58 ¥ /$ ton) are both 
Table 10 Simulation results (ED with ET, carbon price is $427 ¥ /$ ton)

\begin{tabular}{|c|c|c|c|c|c|c|c|}
\hline \multirow[t]{2}{*}{ GenCos } & \multirow{2}{*}{$\begin{array}{l}\text { Generation } \\
\text { (billion } \mathrm{kWh} \text { ) }\end{array}$} & \multirow{2}{*}{$\begin{array}{l}\text { Profit in the electricity } \\
\text { market (billion } ¥ \text { ) }\end{array}$} & \multirow{2}{*}{$\begin{array}{l}\text { Emissions } \\
\text { (million ton) }\end{array}$} & \multicolumn{2}{|c|}{ Grandfathering (million ton) } & \multicolumn{2}{|c|}{ Benchmarking (million ton) } \\
\hline & & & & $\begin{array}{l}\text { Allowances } \\
\text { allocated }\end{array}$ & $\begin{array}{l}\text { Emission } \\
\text { balance }\end{array}$ & $\begin{array}{l}\text { Allowances } \\
\text { allocated }\end{array}$ & $\begin{array}{l}\text { Emission } \\
\text { balance }\end{array}$ \\
\hline COAL_H & 3.15 & 1.27 & 2.99 & 23.13 & 20.14 & 2.59 & -0.40 \\
\hline COAL_M & 9.68 & 3.82 & 8.51 & 12.96 & 4.45 & 7.71 & -0.8 \\
\hline COAL_L & 46.45 & 18.08 & 38.10 & 22.17 & -15.93 & 35.14 & -2.96 \\
\hline GAS_H & 4.07 & 0.76 & 1.69 & 0.84 & -0.85 & 1.55 & -0.14 \\
\hline GAS_L & 28.03 & 6.55 & 9.92 & 4.91 & -5.01 & 10.65 & 0.73 \\
\hline OIL & 0.00 & 0.00 & 0.00 & l & l & l & l \\
\hline TOTAL & 91.38 & 30.48 & 61.21 & 64.01 & 2.80 & 57.64 & -3.57 \\
\hline
\end{tabular}

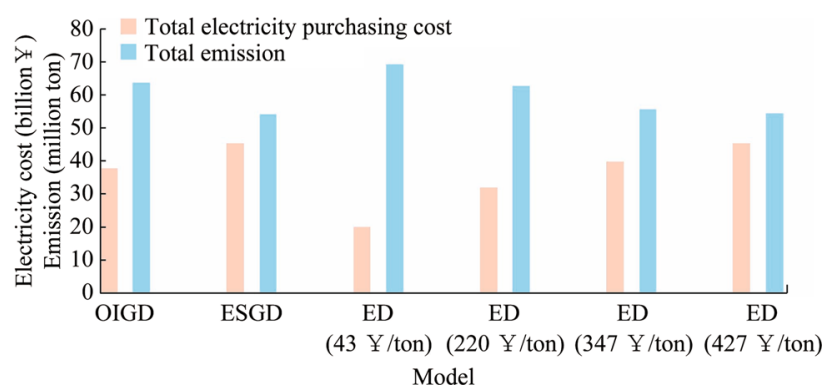

Fig. 2 Total power purchase cost and emissions

inadequate to motivate emission reduction. The maximum carbon price in the EU ETS was $32 € /$ ton in 2006, equivalent to $319.36 ¥ /$ ton (according to the 2006 exchange rate $9.98 ¥ / €)$, and this could be sufficient to provide a substantial incentive.

\subsubsection{Power dispatching model plays a significant role in fulfilling emission reduction task}

The different objective functions of dispatching models result in different emission reduction effects and electricity purchasing cost as shown in Fig. 2. Under ED, if the carbon price is $43 ¥ /$ ton, system emissions increase by $9.0 \%$ compared to those under PD. Only when the carbon price rises to $220 ¥ /$ ton are the system emissions about equal to those under PD. And only when the carbon price is elevated to $427 ¥ /$ ton are the system emissions about equal to those under ESGD.

Under ESGD, the emission reduction task can be achieved with lowest electricity purchasing cost, because the generation quantity and price are rigidly regulated by authorities. In this case, GenCos are exposed to emission price risk, as their emission cost cannot be covered in the electricity market. Therefore, several economic compensation mechanisms should be set up for GenCos to ensure long-term electricity adequacy when reducing emissions. While under ED, as emission costs can be passed through to the electricity price, the load service entity or the end users will be exposed to emission price risk.

Obviously, the power dispatching models play a significant role in fulfilling the emission reduction target. The impact of carbon pricing on electricity prices should be studied carefully before implementing a national level ETS, especially when China is carrying out a new round of electricity reform.

\subsubsection{Strategic behaviors of market participants should be considered in studying electricity and emission market}

In this paper, GenCos report their marginal generation cost to the electricity market as can be found in Section 2.2.3, assuming no strategic behaviors in either the electricity or the emission market. In fact, GenCos can make flexible trading strategies in the emission market to minimize purchasing cost or maximize income from sales, as well as in the electricity market. A good trading strategy can help in reducing GenCos' emission cost and in winning an advantageous position in the competitive market.

It is important to consider strategic behaviors in designing a well-functioning emission market. However, it is a challenge to represent market participants' strategic behaviors in modeling and simulation. In our previous work, a hybrid simulation method combining experimental and computational economics was proposed to model market behaviors, and this has been applied in modelling GenCos' trading behavior in an emission market [33]. Follow-up research will focus on the interaction between electricity and emission markets considering the strategic behaviors of market participants, based on the hybrid simulation method developed by the authors. 


\section{Conclusion}

GenCos are the primary participants in the emission market, and the allowance allocation for them is one of the most important tasks when designing the national ETS. Meanwhile, further electricity reform is underway in China, and the power dispatching model will be transformed into a market based mechanism. On one hand, different emission allowance methods will affect GenCos' position in the emission market, and on the other hand the emission price may affect the GenCos' competitiveness in electricity market. Against this background, based on a simplified generation mix of one provincial power system in China, this paper analyzes the combined effects of different initial allowance allocation methods and power dispatching models on power system emission reductions. Based on simulation results and discussions, several policy implications are highlighted to help to design an effective emission market in China.

Acknowledgements This work was supported by The National Key Research and Development Program of China (Basic Research Class 2017YFB0903000) - Basic Theories and Methods of Analysis and Control of the Cyber Physical Systems for Power Grid, the State Grid Corporation of China "Key technologies research on carbon asset management of transmission company" and Major Consulting Project of Chinese Academy of Engineering (No. 2016-ZD-07).

Open Access This article is distributed under the terms of the Creative Commons Attribution 4.0 International License (http:// creativecommons.org/licenses/by/4.0/), which permits unrestricted use, distribution, and reproduction in any medium, provided you give appropriate credit to the original author(s) and the source, provide a link to the Creative Commons license, and indicate if changes were made.

\section{References}

[1] Stern N (2007) The economics of climate change: the stern review. Cambridge University Press, Cambridge

[2] Zeng WG, Feng S (2015) The terms of capacity-building in Paris agreement: achievement, imperfection and expectation. Environ Prot 43(24):39-42

[3] Wang Q (2013) China has the capacity to lead in carbon trading. Nature 493(7432):273

[4] Kuroda K, Magori H, Ichimura T et al (2015) A hybrid multiobjective optimization method considering optimization problems in power distribution systems. J Mod Power Syst Clean Energy 3(1):41-50. doi:10.1007/s40565-015-0096-0

[5] Qiu J, Dong ZY, Zhao JH et al (2015) A low-carbon oriented probabilistic approach for transmission expansion planning. J Mod Power Syst Clean Energy 3(1):14-23. doi:10.1007/ s40565-015-0105-3

[6] Feng ZH, Wei YM, Wang K (2012) Estimating risk for the carbon market via extreme value theory: an empirical analysis of the EU ETS. Appl Energy 99(99):97-108

[7] Schmidt TS, Schneider M, Rogge KS et al (2012) The effects of climate policy on the rate and direction of innovation: a survey of the EU ETS and the electricity sector. Environ Innov Soc Transit 2(2):23-48

[8] Fan Y, Jia JJ, Wang X et al (2017) What policy adjustments in the EU ETS truly affected the carbon prices? Energy Policy 103:145-164

[9] Bel G, Joseph S (2015) Emission abatement: untangling the impacts of the EU ETS and the economic crisis. Energy Econ 49:531-539

[10] Ahn J (2014) Assessment of initial emission allowance allocation methods in the Korean electricity market. Energy Econ 43(2):244-255

[11] Xiong L, Shen B, Qi SZ et al (2017) The allowance mechanism of China's carbon trading pilots: a comparative analysis with schemes in EU and California. Appl Energy 185:1849-1859

[12] Cong R, Lo A (2017) Emission trading and carbon market performance in Shenzhen, China. Appl Energy 193:414-425

[13] Qi SZ, Wang BB, Zhang JH (2014) Policy design of the Hubei ETS pilot in China. Energy Policy 75:31-38

[14] Fan Y, Wu J, Xia Y et al (2016) How will a nationwide carbon market affect regional economies and efficiency of $\mathrm{CO}_{2}$ emission reduction in China? China Econ Rev 38:151-166

[15] Yang L, Li FY, Zhang X (2016) Chinese companies' awareness and perceptions of the emissions trading scheme (ETS): evidence from a national survey in China. Energy Policy 98:254-265

[16] Ausubel LM, Cramton P (2010) Virtual power plant auctions. Util Policy 18(4):201-208

[17] Cramton P, Kerr S (2002) Tradable carbon permit auctions: how and why to auction not grandfather. Energy Policy 30(4):333-345

[18] Zhou X, James G, Liebman A et al (2010) Partial carbon permits allocation of potential emission trading scheme in Australian electricity market. IEEE Trans Power Syst 25(1):543-553

[19] Uddin N, Holtedahl P (2013) Emission trading schemes-avenues for unified accounting practices. J Clean Prod 52(4):46-52

[20] Åhman M, Burtraw D, Kruger J et al (2007) A ten-year rule to guide the allocation of EU emission allowances. Energy Policy 35(3): 1718-1730

[21] Neuhoff K, Martinez KK, Sato M (2006) Allocation, incentives and distortions: the impact of EU ETS emission allowance allocations to electricity sector. Clim Policy 6(1):73-91

[22] Wang JH (2009) Anti-monopoly and regulation theory and policy. Economy \& Management Publishing House, Beijing

[23] Yan Y, Ma K, Yu Z et al (2007) Primary research on improvement in generation dispatching mode to implement energy conservation and environmental protection and economic dispatching. Electr Power 40(6):6-9

[24] Wei XH, Hu ZY, Yang L (2012) Analysis and suggestions for existing evaluation indices of open and impartial power dispatching. Autom Electr Power Syst 36(20):109-112

[25] Liu TQ, Yang YL, Li XY et al (2010) Energy saving generation dispatch for sustainable development of energy utilizing in China. In: Proceedings of the 2010 Asia-pacific power and energy engineering conference, Chengdu, China, 28-31 Mar 2010, $4 \mathrm{pp}$

[26] (2007) National development and reform commission: energy saving power generation dispatching pilot project is about to commence. Available via DIALOG. http://www.gov.cn/gzdt/ 2007-08/27/content_728247.htm. Accessed 29 June 2016

[27] Chen ZH (2015) New power market reformation is the inevitable choice of energy revolution. South Energy Constr 2(3): 17-22

[28] Ding Y, Yang HL (2013) Promoting energy-saving and environmentally friendly generation dispatching mode in China: phase development and case studies. Energy Policy 57(6):109-118 
[29] Li CB, Liu Y, Cao YJ et al (2011) Consistency evaluation of low-carbon generation dispatching and energy-saving generation dispatching. Proc CSEE 31(31):94-101

[30] Xue YS, Huang J, Wen FS et al (2011) Mutual influences between emission congestion and transmission congestion. Autom Electr Power Syst 35(15):6-12

[31] Jiang C, Xue YS, Huang J et al (2014) Bilateral emission trading behaviors analysis based on human-subjected experiment. In: Proceedings of the 2014 international conference on power system technology, Chengdu, China, 20-22 Oct 2014, 7 pp

[32] Huang J, Xue YS, Jiang C (2015) An experimental study on emission trading behaviors of generation companies. IEEE Trans Power Syst 30(2):1076-1083

[33] Jiang C, Xue YS, Huang J et al (2014) Modeling multi-agent in carbon emission market based on experimental economics simulations. Autom Electr Power Syst 38(17):80-86

[34] Point Carbon (2010) Carbon 2010: return of the sovereign. Available via DIALOG. http://www.environme ntportal.in/content/307107/carbon-2010-return-of-the-sovereign/. Accessed 24 Aug 2017

Chao JIANG received his B.Sc. degree from Nanjing University of Science \& Technology, Nanjing, China, in 2010. Currently, he is pursuing the Ph.D degree at Nanjing University of Science \& Technology. His research interests include power market and emission market modeling, experimental economics and environmental policies.

Yusheng XUE received his Ph.D. degree in Electrical Engineering from the University of Liege (Belgium) in 1987. He became a Member of Chinese Academy of Engineering in 1995. He is now the Honorary President of State Grid Electric Power Research Institute (SGEPRI), State Grid Corporation of China. His research interests include nonlinear stability, control and power system automation.

Jie HUANG received his Ph.D. degree from Nanjing University of Science \& Technology in 2011. He is now a senior engineer in State
Grid Electric Power Research Institute (SGEPRI), State Grid Corporation of China. His research interests include electricity market modeling and simulation, risk management, and policy issues related with emission trading.

Feng XUE received his Ph.D. degree from the University of Bath, $\mathrm{UK}$ in 2008. His main research field is power system analysis and control.

Fushuan WEN received the B.E. and M.E. degrees from Tianjin University, Tianjin, China, in 1985 and 1988, respectively, and the Ph.D. degree from Zhejiang University, Hangzhou, China, in 1991, all in electrical engineering. He joined Zhejiang University in 1991 and has been a full professor and the director of the Institute of Power Economics and Information since 1997. He was the deputy dean of the School of Electrical Engineering in South China University of Technology, Guangzhou, China, from 2005 to 2009. Since May 2014, he has been a professor with Brunei University of Technology, Brunei. His research interests lie in power industry restructuring, power system alarm processing, fault diagnosis and restoration strategies, as well as smart grids and electric vehicles.

Kang LI received the B.Sc. degree from Xiangtan University, Hunan, China, in 1989, the M.Sc. degree from the Harbin Institute of Technology, Harbin, China, in 1992, and the Ph.D. degree from Shanghai Jiao Tong University, Shanghai, China, in 1995. He is currently a Professor of intelligent systems and control with Queen's University Belfast, Belfast, U.K. His current research interests include nonlinear system modeling, identification, and control, bio-inspired computational intelligence, fault diagnosis and detection, with recent applications on power systems and renewable energy, polymer extrusion processes, bioinformatics with applications on food safety, healthcare, and biomedical engineering. 